\title{
Violência simbólica de gênero: estudo comparativo sobre o ambiente acadêmico em escolas de educação profissional e tecnológica
}

Symbolic gender violence: a comparative study on the academic environment in professional and technological education schools

Eloiza Helena Gonçalves Maia', Raquel Quirino

${ }^{1}$ Centro Federal de Educação Tecnológica de Minas Gerais, Programa de Pósgraduação em Educação Tecnológica, Brasil, e-mail: eloizagm@terra.com.br, quirinoraquel@hotmail.com, ORCID: https://orcid.org/0000-0002-2495-3725, https://orcid.org/0000-0001-9256-656X

\author{
ART I C LE IN F O \\ Article history: \\ Received 2020-06-01 \\ Accepted 2021-05-04 \\ Available online 2021-05-04
}

Palavras-chave: Mulher. Ambientes Educacionais. Violência Simbólica. Relações de Poder.

Keywords: Woman. Educational Environments. Symbolic Violence. Power Relations.

RESUMO. Este artigo tem por objetivo trazer um breve estudo comparativo sobre o cenário da violência simbólica de gênero em ambientes educacionais brasileiros, mais precisamente em escolas federais de educação profissional e tecnológica. Foram escolhidos um TCC, uma dissertação e um artigo para o estudo comparativo, para averiguar se a violência se manifesta ou não em contextos educacionais e como é enfrentada pelas mulheres para se manterem na trajetória de formação escolhida/ profissão. Os cenários escolhidos foram instituições de dois estados do NordesteUniversidade Federal da Bahia- UFB e Universidade Federal do Ceará- UFC e duas da região Sul do país, Universidade Tecnológica Federal do Paraná- UTFPR e o Instituto Federal de Santa Catarina- IFSC. A escolha dos locais se justifica pela possibilidade de se comparar regiões diferentes do país verificando se esses comportamentos dependem ou não de cultura local. A partir da teoria sobre Violência Simbólica de Gênero, essas pesquisas trouxeram questões interessantes sobre as mais diversas formas de violência sofrida pelas mulheres. Por instrumentos foram utilizados o levantamento de pesquisas bibliográficas e o estudo comparativo de dados. A pesquisa é exploratória, de cunho qualitativo e o método é o dialético. $O$ resultado nos mostrou claramente a presença da violência simbólica de gênero em ambientes acadêmicos. Mostrou-nos ainda que temos muita luta pela frente para conscientizar a sociedade sobre mudanças nessa relação social, que traz embutida relações de poder entre os sexos, distribuídas de forma desigual, cabendo sempre à mulher uma posição subalterna na organização social.

ABSTRACT. This article aims to bring a brief comparative study on the scenario of symbolic gender violence in Brazilian educational environments, more precisely in federal schools of professional and technological education. A CBT, a dissertation and an article were chosen for the comparative study, to ascertain whether or not violence manifests itself 
in educational contexts and how women to stay on the chosen training path / profession face it. The chosen scenarios were institutions from two states in the Northeast - Federal University of Bahia - UFB and Federal University of Ceará - UFC and two in the South of the country, Federal Technological University of Paraná - UTFPR and the Federal Institute of Santa Catarina - IFSC. The choice of locations is justified by the possibility of comparing different regions of the country, checking whether these behaviors depend on local culture or not. Based on the theory of Symbolic Gender Violence, these surveys raised interesting questions about the most diverse forms of violence suffered by women. The instruments used were the survey of bibliographic research and the comparative study of data. The research is exploratory, qualitative and the method is dialectical. The result clearly showed us the presence of symbolic gender violence in academic settings. It also showed us that we have a lot of struggle ahead to make society aware of changes in this social relationship, which brings built-in power relations between the sexes, unevenly distributed, with women always having a subordinate position in social organization.

\section{Introdução}

Com o objetivo de trazer um breve estudo comparativo sobre o cenário da violência simbólica de gênero em ambientes educacionais brasileiros, mais precisamente em escolas federais de educação profissional e tecnológica, busca-se, como base teórica, um TCC, uma dissertação e um artigo cujos focos de pesquisa se convergem para essa temática.

Sendo "violência" e "gênero" categorias historicamente construídas, "a percepção social da violência não é única e nem universal” (GROSSI, 1994, p. 482). A violência contra a mulher é resultante de um conceito que abrange desde a sua forma mais concreta possível até a mais velada. Mesmo com a ampliação do conceito, ainda são escassas as pesquisas que evidenciam a forma velada de violência - a violência simbólica, traduzida pelo assédio sexual e moral, vivenciadas pelas mulheres diariamente nas escolas e nos ambientes de trabalho. Discutir, analisar e tentar conscientizar as pessoas sobre mudanças nessa forma de tratar a questão são urgentes e necessárias.

Inicialmente, torna-se necessário, conhecer o conceito de "violência" que SAFFIOTI define em seu livro Gênero, Patriarcado, Violência. Segundo a autora, na página 17, violência conceitua-se como sendo a ruptura de qualquer forma de integridade da vítima: integridade física, integridade psíquica, integridade sexual, integridade moral, observando-se ainda que apenas as integridades psíquica e moral situam-se fora do palpável; a não ser que a violência psíquica enlouqueça a vítima, tornando-se assim também palpável.

Assim, ampliando um pouco mais, chega-se ao conceito de violência simbólica, que, segundo Bourdieu (2012), é aquela que acontece de forma sutil, insensível e invisível a suas próprias vítimas. Para BOURDIEU, 2007, a dominação masculina está presente em todas as áreas na sociedade, caracterizando-se através do poder que o dominante exerce sobre o dominado, sem que o dominante precise exercer nenhuma forma de coerção física sobre o dominado, porque a "força ou poder simbólico" tem essa "magia" de coagir o dominado. Esse poder é carregado de pressupostos, conceitos e valores que foram introjetados no dominado pelas estruturas que fundamentam essa dominação.

Ainda como cita Bourdieu (2011, p. 7) "o poder simbólico é um poder de construção da realidade que tende a estabelecer uma ordem gnosiológica: o sentido imediato do mundo". E isso permite que a violência simbólica se camufle por detrás 
de esquemas inconscientes de percepção e as vítimas, por sua vez, não reconhecem ou percebem tal violência. Os princípios da dominação masculina legitimam o homem como sexo dominante, privilegiando-o na ocupação de posições de poder nas esferas social, política e econômica. E como ressalta o autor: "a força da ordem masculina se evidencia no fato de que ela dispensa justificação; a visão androcêntrica impõe-se como neutra e não tem necessidade de se enunciar em discursos que visem a legitimá-la” (BOURDIEU, 2002, p.18).

Grossi (1994) chama atenção para os casos de assédio sexual envolvendo subordinados intimidados que se demitem ou demissões por "justa causa" sobre fatos forjados e revela o quanto é difícil a denúncia, uma vez que as vítimas estão sujeitas às relações de poder. No entanto, a grande imprensa tem trazido casos envolvendo professores, autoridades religiosas, chefes imediatos, etc. Por sua vez, o assédio moral está relacionado "a um esforço repetitivo de desqualificação de uma pessoa por outra, podendo conduzir ou não ao assédio sexual” (FREITAS, 2001, p. 9).

A violência simbólica torna-se parte do cotidiano das pessoas que não mais a percebem como violência. Bourdieu percebia a estrutura universitária como um fator que contribuía para a manutenção ou propagação da violência simbólica, e, para ele, a estrutura acadêmica apresenta "um dos princípios mais decisivos da mudança nas relações entre os sexos, devido às contradições que nela ocorrem e às que ela introduz" (1999, p.105).

Atendo-se não apenas à violência manifesta e explícita, mas à violência simbólica caracterizada como assédio moral e assédio sexual, investiga-se as consequências e as sequelas desses fenômenos, cometidos contra as mulheres, em ambientes educacionais. Os resultados mostram que a violência simbólica de gênero é bastante frequente no meio acadêmico. O preconceito e a prática dessa violência independe de cultura regional. Torna-se urgente a visibilidade desse tema, pois as pesquisas sobre essa temática ainda são bastante escassas nos programas de pósgraduação no Brasil.

\section{Metodologia}

A análise desenvolvida para a elaboração deste artigo foi uma pesquisa exploratória, de abordagem qualitativa, que se utiliza da técnica do estudo comparativo de dados. No primeiro momento, foram feitas consultas usando-se como descritores "violência simbólica", "assédio sexual" e "ambientes acadêmicos" nas seguintes bases de dados: Biblioteca Digital Brasileira de Teses e Dissertações BDTD, na qual foi selecionada a dissertação Assédio sexual em uma instituição de ensino superior: a percepção das servidoras da Universidade Federal do Ceará (UFC), de Érica Cavalcante Lima. Foi consultada também, a base de dados de TCCs/monografias da Biblioteca universitária da UFSC, da qual foi selecionado o TCC violência de gênero na escola: abuso/assédio sexual e relações de poder, cuja autoria é de Flavia Maia Moreira. Além das duas produções, analisa-se o artigo violência simbólica de gênero em duas universidades brasileiras, das autoras Lindamir Salete Casagrande e Ângela Maria Freire de Lima e Souza, publicado no livro Violência, gênero e diversidade, organizado pelos autores Clóvis Wanzinack e Marcos Cláudio Signorelli.

No segundo momento, faz-se uma leitura criteriosa das três pesquisas e coletase os principais dados como título, objetivos, metodologias, teoria de base, sujeitos de pesquisa, principais resultados obtidos. Em seguida, apontam-se algumas conclusões de cada um dos estudos. Por último, nas considerações finais, são feitas anotações que permitem um comparativo do que há em comum nas três pesquisas. 
Os instrumentos utilizados são pesquisa bibliográfica e a análise comparativa de dados. O foco da pesquisa tem como objeto um breve estudo comparativo sobre o cenário da violência simbólica de gênero em ambientes educacionais brasileiros, mais precisamente em escolas federais de educação profissional e tecnológica. Em seguida, são feitas as análises e interpretações dos dados. Diante dos resultados, busca-se apontar alguns caminhos como pontos de reflexão, para que cada vez mais se possa avançar na questão da igualdade de gêneros.

\section{Desenvolvimento da pesquisa}

A partir da análise do TCC, da dissertação e do artigo, descreve-se a seguir as principais observações. Em seguida, fazem-se as discussões comparativas referentes aos resultados encontrados em cada uma das produções analisadas.

\subsection{Trabalho de conclusão de curso (TCC)}

O TCC violência de gênero na escola: abuso/assédio sexual e relações de poder, cuja autoria é de Flavia Maia Moreira, sob a orientação da professora Doutora Suzana Tolfo, foi apresentado como trabalho final no Curso de Especialização em Gênero e Diversidade na Escola, no Centro de Filosofia e Ciências Humanas da Universidade Federal De Santa Catarina em 2016, Florianópolis.

O objetivo principal deste trabalho foi compreender a percepção acerca da violência de gênero relacionada ao ambiente escolar, em particular quanto aos indícios de abuso/assédio/violência sexual, utilizando como campo de estudo o Instituto Federal de Santa Catarina (IFSC), Campus São José.

A pesquisa foi quali-quantitativa, através de questionário semiestruturado. $O$ estudo foi realizado com estudantes entre 16 e 20 anos, da $5^{\underline{a}}$ a $8^{\text {a }}$ fase dos cursos técnicos Integrados do IFSC, Campus São José.

O silenciamento das vítimas na escola reforça a naturalização das desigualdades de gênero presentes na nossa sociedade, contribuindo para uma forma de violência que o sociólogo francês Pierre Bourdieu (1997) conceituou como simbólica.

Os resultados mostraram uma clara diferença na vivência dessas situações de violência no ambiente escolar entre os gêneros, tanto na sua tipologia quanto no desconforto e na intimidação. Também ficou claro que essas situações ocorreram desde o Ensino Fundamental, intensificando-se no Ensino Médio, sem que a escola em nenhum momento apareça como protagonista no acolhimento dessas vítimas e no combate a esse tipo de violência.

Apesar de também terem sido relatadas experiências por parte dos meninos, são as meninas que relatam terem vivenciado o maior número de situações de abuso e de assédio sexual na escola, por parte de professores e funcionários. As situações mais frequentemente relatadas estão muito mais no campo da visão erotizada dessas adolescentes por adultos que se utilizam mais de técnicas de sedução do que de ameaça para a satisfação de seus desejos sexuais.

Apesar de não haver um consenso na literatura jurídica sobre a caracterização desse crime no ambiente escolar, pela falta da caracterização do vínculo empregatício, fica evidente que a posição hierarquicamente superior de um funcionário da escola, principalmente no caso de professores, caracteriza uma relação de poder entre desiguais, independentemente da idade da vítima. Muitos relatos das próprias vítimas "inocentaram" professores, possivelmente por medo de retaliação e 
de perseguição, como se as atitudes dos professores pudessem ser justificadas pela provocação ou pelo consentimento das próprias vítimas.

Outro fator importante revelado nesse estudo é a total ausência da escola na identificação, no combate e na prevenção dessa violência no seu interior. Assim, quando o abuso ou o assédio sexual ocorre dentro da escola, esse é perpetrado por educadores e a Instituição não comunica ao conselho tutelar, a escola está se omitindo e ferindo a condição peculiar de pessoa em desenvolvimento, de acordo com o art. 70B do Estatuto da Criança e do Adolescente. Além disso, a omissão da escola contribui grandemente para a perpetuação da violência simbólica contra meninas e mulheres, o que pode gerar sequelas emocionais permanentes.

O Instituto Federal de Santa Catarina, apesar de ter tido expressivo crescimento nos últimos anos e de ter uma reconhecida excelência na sua oferta formativa, assim como na qualidade do seu quadro docente e técnico, avançou muito pouco quanto ao combate à desigualdade de gênero. A Instituição continua caracterizada por um domínio masculino e pela violência simbólica contra as mulheres. O desafio institucional não deve ser encerrado com o oferecimento de iguais oportunidades de acesso à educação: é preciso também garantir condições equivalentes, para que todas as alunas permaneçam no sistema escolar e sejam bemsucedidas.

\subsection{A dissertação}

A dissertação de mestrado intitulada Assédio sexual em uma instituição de ensino superior: a percepção das servidoras da Universidade Federal do Ceará (UFC), de Érica Cavalcante Lima, orientada pela professora Dr. ${ }^{\text {a }}$ Maria Elias Soares, foi apresentada ao curso de Políticas Públicas e Gestão da Educação Superior em 2017, na Universidade Federal do Ceará-Fortaleza. Esse trabalho possui os seguintes objetivos: investigar a percepção das servidoras lotadas na Pró-Reitoria de Gestão de Pessoas da Universidade Federal do Ceará, no tocante ao conceito de Assédio Sexual, verificar quais fatores levam à identificação do assédio, apreender o modo como percebem a instituição em que trabalham frente a essa prática e, por fim, propor melhorias no ambiente laboral da Organização, com ênfase na prevenção desse crime.

Para a elaboração dessa pesquisa, de caráter qualitativo, aplicou-se questionário composto por perguntas objetivas e subjetivas a 58 trabalhadoras, utilizando, na análise dos dados, os procedimentos metodológicos do Discurso do Sujeito Coletivo. Foram utilizadas como principais teorias de base: BARRETO, Margarida Maria Silveira, BEAUVOIR. Simone de. BOURDIEU, Pierre, FREITAS, M. E., HIRIGOYEN, Marie-France, LOURO, Guacira Lopes.

$O$ assédio sexual pode ser definido como uma invasão aos limites da intimidade do outro, como um tipo de constrangimento e, portanto, como uma falta de respeito para quem o sofre. Pode ser considerado, ainda, como uma forma de opressão, visto que, quase sempre, essa invasão tem como elemento caracterizador uma relação de poder entre o agressor e a vítima e, nesse sentido, costuma acontecer, sobretudo, por parte dos homens contra as mulheres.

Essa pesquisa, primeiramente, buscou descrever todos os aspectos mais importantes acerca do que, de fato, significa o assédio sexual. Em seguida, foi proposto um retrospecto histórico acerca do trabalho feminino, com o fim de demonstrar o porquê de serem as mulheres as principais vítimas desse tipo de agressão. Pôde-se apreender que as trabalhadoras pesquisadas têm sólido conhecimento acerca dessa prática, visto que entendem quais são os seus principais elementos caracterizadores, quais sujeitos podem ser vítimas e agressores, quais 
causas possivelmente motivam a prática e quais são as sensações despertadas nas pessoas que o sofrem, bem como quais são as formas de prevenção e de combate à prática. Pôde-se concluir, dessa forma que elas não consideram a UFC como uma instituição segura, no sentido de prevenção e de combate à prática de assédio sexual, e dão significativas sugestões para auxiliar a Instituição a proceder sobre esse aspecto.

A Universidade Federal do Ceará não tem desenvolvido qualquer trabalho de informação, prevenção ou de combate em relação ao crime de assédio sexual em seus espaços laborais. Conforme ressalta Freitas (2001), as organizações que, quase sempre, têm homens à frente dos postos de comando e de gerenciamento, ainda não se atentaram para a gravidade de problemas como o assédio sexual e, nesse sentido, costumam assumir posicionamentos negligentes, no tocante a temas dessa natureza.

Quando uma instituição se omite a assumir posicionamentos resolutivos no combate a problemas dessa natureza, é dificultada a promoção de um ambiente laboral inteiramente saudável e além disso, essa corre riscos de formar uma imagem negativa de si, frente aos seus colaboradores internos e externos, bem como de prejudicar-se no desempenho pleno de suas atividades. Essa pesquisa procurou ressaltar a necessidade de as organizações, em especial a Universidade Federal do Ceará, disponibilizarem parte da sua atenção para a questão do assédio sexual o qual, por vezes, é encarado como um problema distante, pouco prejudicial e menos importante, mas que, na verdade, causa bastante inquietação para as partes que estão vulneráveis.

Esse trabalho concorda com a perspectiva demonstrada por importantes estudos acerca dessa temática: de que o assédio sexual é nocivo ao estabelecimento de condições dignas, justas e igualitárias aos trabalhadores e que, desse modo, ele precisa ser prevenido e combatido de quaisquer ambientes laborais. Faz-se necessário, portanto, a difusão de mais informações sobre essa violência, sobretudo nas organizações, visto que são ambientes propícios para esse tipo de agressão. Acredita-se que esse trabalho pode contribuir para a melhoria da Gestão Estratégica da Universidade Federal do Ceará, pois, ao trazer elementos que tratam da percepção de uma parcela importante do seu capital humano, acerca de um assunto que tem representado um relevante desafio ao bom funcionamento das organizações, ele poderá ajudar a Instituição a encontrar medidas que dificultem cada vez mais a prática desse ato indecoroso, que denigre quaisquer relações de trabalho onde ocorre.

\subsection{0 artigo}

O artigo- violência simbólica de gênero em duas universidades brasileiras, das autoras Lindamir Salete Casagrande Ângela Maria Freire de Lima e Souza, Programa de Pós-Graduação em Estudos Interdisciplinares sobre Mulheres, Gênero e Feminismo - PPGNEIM, Universidade Federal da Bahia (UFBA), traz uma pesquisa desenvolvida simultaneamente em dois estados brasileiros, sendo estes Bahia e $\mathrm{Pa}$ raná.

O objetivo da pesquisa foi analisar os cursos de licenciatura e engenharia da UFBA e da UTFPR sob a perspectiva de gênero. "Esta pesquisa foi baseada na metodologia qualitativa na qual utilizamos como instrumento de coleta de dados a 'entrevista virtual'". Para tal, foi enviado aos/às estudantes de Engenharia Mecânica e Civil e das licenciaturas em Letras e Matemática da UTFPR, campi Curitiba e Pato Branco, e da UFBA, um formulário/questionário no qual foi apresentada a pesquisa e, em seguida, um quadro para o levantamento dos dados socioeconômicos e cinco perguntas abertas. A base teórica sustenta-se em Pierre Bourdieu. 
Nesse capítulo o olhar foi voltado para os cursos de engenharia e licenciatura de duas universidades federais brasileiras buscando identificar nos depoimentos de seus/suas estudantes indícios de violência simbólica. Essas dificuldades recaem, de modo especial, sobre as mulheres. Há um estranhamento da comunidade acadêmica e da sociedade em geral quando elas decidem adentrar nas engenharias, de modo especial, na engenharia mecânica, que ainda se constituem em redutos masculinos. Esse estranhamento ocorre com base nos estereótipos de que as mulheres não têm condições físicas e intelectuais de acompanhar um curso tão difícil. Também se sustenta na ideia equivocada de que as mulheres não seriam naturalmente dotadas de habilidades intelectuais exigidas para a área das Ciências Exatas, como raciocínio abstrato, objetividade, dentre outras. Daí espera-se que elas se dediquem a cursos mais leves ou mais adequados às suas tendências "naturais", como o cuidado, a empatia a atenção para a estética, etc. Nesse tipo de pensamento, revelam-se todos os estereótipos de gênero que associam as mulheres à fragilidade, à incapacidade, uma constante referência ao conceito do "sexo frágil".

Mas onde está esta fragilidade? Como, nos dias atuais, nos quais as mulheres têm dado inúmeras demonstrações de capacidade, esse preconceito ainda se sustenta? Até quando o meio universitário, assim como, de resto, a sociedade, vai continuar a se apresentar como um ambiente muitas vezes hostil para mais da metade da população? Nas páginas anteriores percebemos que a violência simbólica se manifesta com base em diversas situações e é praticada tanto por estudantes quanto por professores/as. Estudantes que atravessam as barreiras que a sociedade insiste em impor têm sua sexualidade, sua beleza, sua capacidade questionada. Eles e elas relatam que se sentem mal com tal situação. Mostram-se cientes do que está ocorrendo no meio acadêmico, porém, muitas vezes, se sentem incapazes de reagir.

As mulheres que participaram dessa pesquisa demonstraram que quando a agressão vem de um colega elas manifestam seu descontentamento e acabam superando as situações constrangedoras e conquistando seus espaços com base no trabalho e no esforço pessoal empregado no decorrer do curso. Porém, quando o/a agressor/a é um/a professor/a suas reações são limitadas pelo temor de serem punidas nas avaliações, que muitas vezes, são subjetivas.

As entrevistas evidenciaram que o meio acadêmico está longe de ser um espaço democrático e igualitário. Estudantes que ousam escolher cursos que, supostamente, são destinados a um dos sexos enfrentam dificuldades que lhes são impostas exclusivamente por pertencer ao outro sexo. Percebe-se que a violência simbólica se manifesta com base em diversas situações e é praticada tanto por estudantes quanto por professores/as. Estes/ as profissionais que deveriam estimular e contribuir para o crescimento de todos e todas igualmente acabam contribuindo para o afastamento das mulheres de carreiras que são valorizadas social e financeiramente. Trata-se de uma postura que não condiz com o papel que se espera de um/a professor/a. Evidencia-se que há a necessidade urgente de se desenvolver ações para que tais situações sejam banidas do meio universitário, pois todos e todas têm condições de fazer o curso que desejarem, desde que estejam disponíveis para eles e elas as mesmas condições de acesso e de permanência.

Ao compararmos as duas universidades, percebemos que não há diferença significativa no que se refere a essa questão. Considerando que as universidades estão inseridas em regiões do país com culturas diferentes, poderíamos encontrar resultados também diferentes. Entretanto, isso não ocorre. Para o preconceito e a violência simbólica, as diferenças culturais que caracterizam as regiões em foco nesse estudo parecem exercer pouca interferência. As agressões e os obstáculos impostos às mu- 
Iheres paranaenses são muito similares aos impingidos às mulheres baianas. Percebe-se que há a necessidade de se desenvolver ações para que tais situações sejam banidas do meio universitário, para que todos e todas tenham condições de fazerem as escolhas de acordo com suas aptidões, anseios e vontades, e, principalmente, encontrem na universidade um ambiente no qual tenham condições de permanência e crescimento igualitário. Todos e todas têm condições de fazer o curso que desejarem, desde que estejam disponíveis para eles e para elas as mesmas condições de acesso e permanência.

\section{Resultados e discussões}

Em relação ao artigo, confirma-se que a violência simbólica se manifesta no meio universitário de diversas formas, em diferentes campos. Seja ela na sexualidade, na aparência física dos/as estudantes, nas supostas diferenças cognitivas entre homens e mulheres, na faixa salarial da futura carreira ou na postura dos professores/as.

Em relação à sexualidade, tanto homens quanto mulheres são questionados quando se escolhe cursos considerados redutos do outro sexo, uma vez que, na percepção da sociedade, existem cursos para o público feminino e cursos para o público masculino. E sempre os considerados femininos são mais desvalorizados. Homens que escolhem cursos considerados femininos são chamados de "gay", e as mulheres que escolhem cursos considerados masculinos são taxadas de "lésbicas", "sapatão". Com isso, áreas do conhecimento podem estar perdendo grandes talentos.

Em relação à aparência física, mulheres que escolhem as engenharias, principalmente mecânica, são consideradas "feias" e também "sapatões". A mulher sempre é considerada menos capacitada intelectualmente do que o homem, por isso é discriminada principalmente quando decide transgredir para as áreas ditas masculinas. No depoimento de pesquisados, fica claro que alguns professores "são mais prestativos com as alunas" e isso pode gerar algumas leituras, inclusive a de assédio sexual. Por exemplo, o/a professor/a considera que a menina/mulher tem mais dificuldade com o conteúdo e, que por isso, precisa de uma atenção especial, de uma proteção.

As profissões tidas como qualificadas são ocupadas por homens, enquanto os trabalhos sem qualificação são atribuídos às mulheres. Quanto ao trabalho propriamente dito, mesmo que as mulheres tenham a mesma capacidade intelectual das de um homem e a mesma formação, sempre terão salários inferiores aos dos homens. A desigualdade de renda entre homens e mulheres no caso brasileiro é resultado de uma inserção, no mercado de trabalho, diferenciada por sexo, na qual a mulher quase sempre está em ocupações precárias, de baixa qualificação e informal.

Já quando se fala do TCC e da dissertação, parte-se para uma violência simbólica no campo do assédio sexual. Aqui, percebe-se que, tanto no processo de formação profissional quanto no exercício da profissão propriamente dita, a mulher sofre agressões e discriminações de forma bem parecida dentro do contexto educacional.

No que diz respeito às alunas do Instituto Federal de Santa Catarina, elas sofrem agressões sexuais por parte de professores e funcionários. A maioria dos casos não são levados a conhecimento da Instituição e acabam tratados como "naturais". As alunas muitas vezes não denunciam esse assédio por medo de retaliação e de perseguição por parte do agressor que, na maioria das vezes, são os próprios professores. Outros fatores que influenciam na falta de denúncia é vergonha, principalmente por 
terem que provar o assédio e passarem por situações constrangedoras, além do próprio discurso velado de que o assédio acontece pela provocação e pelo consentimento da vítima. Nesse caso, ainda, as alunas geralmente são menores de idade, o que torna o fato mais grave ainda. O silenciamento é muitas vezes usado como forma de resistência para as vítimas se manterem em suas trajetórias. A escola não tem nenhum programa de combate e de prevenção a esse tipo de violência sofrido pelas mulheres alunas.

Situação parecida é enfrentada pelas servidoras da Universidade Federal do Ceará. Apesar de passarem pela situação do assédio sexual, as trabalhadoras pesquisadas têm sólido conhecimento acerca dessa prática, visto que entendem quais são elementos caracterizadores; quais sujeitos se enquadram nas condições de vítimas e de agressores, quais causas possivelmente motivam a prática e quais sensações são despertadas nas pessoas que o sofrem, além de saberem das formas de prevenção e de combate à prática. Foi possível também concluir que elas não consideram a UFC como uma instituição segura no sentido de prevenir e de combater a prática de assédio sexual, além de elencarem significativas sugestões para auxiliar a Instituição a proceder nesse aspecto.

\section{Considerações Finais}

Em relação à violência simbólica de gênero, comparando a monografia, a dissertação e 0 artigo, percebe-se que 0 quadro apresentado não tem muitas diferenças. Pelo contrário, eles têm muito em comum. Nota-se que tanto no ensino fundamental, quanto no ensino médio, na graduação ou no ambiente de trabalho, ela é bastante comum e presente no meio acadêmico.

As agressões e os obstáculos impostos às mulheres baianas, cearenses, paranaenses e de Santa Catarina são muito similares. Para o preconceito e para a violência simbólica, as diferenças culturais que caracterizam as regiões em foco neste estudo parecem exercer pouca interferência. Nesse contexto a mulher sempre é colocada numa posição subalterna, no que se trata da organização social e organizacional.

Além disso, percebe-se que há poucos estudos que abordam essa violência simbólica de gênero em ambientes acadêmicos, principalmente no que tange ao assédio sexual. E, se essas situações são reais e presentes no cotidiano escolar, porque ainda são tão camufladas? Porque suas vítimas não denunciam? Quais motivos falam mais alto na hora de tornar público tais acontecimentos? A instituição é conivente?

Diante de tantas perguntas, torna-se urgente aumentar as pesquisas, para dar maior visibilidade a esse tipo de prática e responder a todos esses questionamentos. É necessário desenvolver ações, para que tais situações sejam extintas do meio universitário, no sentido de que todos e todas tenham condições de fazerem as escolhas de acordo com suas aptidões, anseios e vontades. E que, principalmente, encontrem na universidade, um ambiente no qual, tenham condições de permanecerem e crescerem de forma igualitária. Todos e todas têm condições de fazer o curso que desejarem, desde que estejam disponíveis para eles e elas as mesmas condições de acesso e permanência. Portanto, confirma-se que ainda há muita luta pela frente na busca da conscientização da sociedade sobre as mudanças necessárias nessa relação social. 


\section{REFERÊNCIAS}

BOURDIEU, Pierre. A dominação masculina. Tradução Maria Helena Kühner. 12. ed. Rio de Janeiro: Bertrand Brasil, 2007. 159 p.

BOURDIEU, Pierre. O poder simbólico. Tradução de Fernando Tomaz. 15 ed. Rio de Janeiro: Bertrand Brasil, 2011. 311p.

BOURDIEU, Pierre. A dominação masculina. Rio de Janeiro: Bertrand Brasil, 2012. CASAGRANDE, Lindamir Salete. SOUZA, Ângela Maria Freire de Lima e. Violência simbólica de gênero em duas universidades brasileiras. In: WANZINACK, Clóvis. SIGNORELLI, Marcos Claudio; (Orgs.). Violência, gênero \& diversidade: desafios para a educação e o desenvolvimento. Rio de Janeiro: Editora Autografia, 2015.

FREITAS, Maria Ester de. Assédio moral e assédio sexual: faces do poder perverso nas organizações. RAE - Revista de Administração de Empresas. v. 41 . n. 2 . Abr./Jun. 2001.

GROSSI, Miriam Pilar. Novas/velhas violências contra a mulher no Brasil. Estudos feministas. Porto Alegre, ano 2, segundo semestre 1994.

LIMA, Érica Cavalcante. Assédio sexual em uma instituição de ensino superior: a percepção das servidoras da Universidade Federal do Ceará (UFC). Orientadora: Maria Elias Soares. 2017. 143f. Dissertação Mestrado em Políticas Públicas e Gestão da Educação Superior, Universidade Federal do Ceará, Fortaleza, Ceará, 2017 MOREIRA, Flávia Maia. Violência de gênero na escola: abuso/assédio sexual e relações de poder. Orientadora: Suzana da Rosa Tolfo. 2016. 56f. TCC Especialização em Gênero e Diversidade na Escola, Universidade Federal de Santa Catarina, Florianópolis, Santa Catarina- 2016

SAFFIOTI, Heleieth. Gênero, patriarcado e violência. São Paulo: Editora Fundação Perseu Abramo, 2004 